IZA DP No. 8580

Leaders as Role Models for the Voluntary Provision of Public Goods

Simon Gächter

Elke Renner

October 2014 


\title{
Leaders as Role Models for the Voluntary Provision of Public Goods
}

\author{
Simon Gächter \\ University of Nottingham, \\ CESifo and IZA \\ Elke Renner \\ University of Nottingham
}

\section{Discussion Paper No. 8580 \\ October 2014}

\author{
IZA \\ P.O. Box 7240 \\ 53072 Bonn \\ Germany \\ Phone: +49-228-3894-0 \\ Fax: +49-228-3894-180 \\ E-mail: iza@iza.org
}

Any opinions expressed here are those of the author(s) and not those of IZA. Research published in this series may include views on policy, but the institute itself takes no institutional policy positions. The IZA research network is committed to the IZA Guiding Principles of Research Integrity.

The Institute for the Study of Labor (IZA) in Bonn is a local and virtual international research center and a place of communication between science, politics and business. IZA is an independent nonprofit organization supported by Deutsche Post Foundation. The center is associated with the University of Bonn and offers a stimulating research environment through its international network, workshops and conferences, data service, project support, research visits and doctoral program. IZA engages in (i) original and internationally competitive research in all fields of labor economics, (ii) development of policy concepts, and (iii) dissemination of research results and concepts to the interested public.

IZA Discussion Papers often represent preliminary work and are circulated to encourage discussion. Citation of such a paper should account for its provisional character. A revised version may be available directly from the author. 
IZA Discussion Paper No. 8580

October 2014

\section{ABSTRACT}

\section{Leaders as Role Models for the Voluntary Provision of Public Goods}

We investigate the link between leadership, beliefs and pro-social behavior. This link is interesting because field evidence suggests that people's behavior in domains like charitable giving, tax evasion, corporate culture and corruption is influenced by leaders (CEOs, politicians) and beliefs about others' behavior. Our framework is an experimental public goods game with a leader. We find that leaders strongly shape their followers' initial beliefs and contributions. In later rounds, followers put more weight on other followers' past behavior than on the leader's current action. This creates a path dependency the leader can hardly correct. We discuss the implications for understanding belief effects in naturally occurring situations.

JEL Classification: $\quad$ C72, C90, H41, Z13

Keywords: leadership, beliefs, experiments, public goods, path dependency, public policy, management

Corresponding author:

Simon Gächter

University of Nottingham

School of Economics

Sir Clive Granger Building

University Park

Nottingham NG7 2RD

United Kingdom

E-mail: simon.gaechter@nottingham.ac.uk 


\section{Introduction}

"Once you as a CEO go over the line, then people think it's okay to go over the line themselves."

Lawrence Weinbach, Head of Unisys (quoted after The Economist, July 27, 2002, p.58)

“... the most common argument legitimizing tax evasion among Swedes is that those in leading positions in society violate the social norms."

Hammar et al. (2009), p. 239

Field evidence on charitable giving, tax evasion, the abuse of the welfare state, criminal behavior, corruption, and corporate culture, suggests that people's own behavior in these domains depends strongly on their beliefs about how others will behave. ${ }^{1}$ Leaders politicians, government officials, and managers - may serve as role models for what is considered appropriate and may thus shape their followers' beliefs about the behavior of others. For instance, leaders who behave too selfishly, evade taxes, consume unwarranted privileges, accept bribes, etc. may induce people to do the same (as suggested by our opening quotes) and may nurture people's beliefs that other people will do the same. This may exacerbate the problem to the extent that people's behavior is not only shaped by the leader's example but also by their beliefs about other people's actions. Of course, if the leader behaves as a positive role model, the opposite conclusions may hold.

Our main contribution is testing this intuition. More generally, we aim to contribute to a better understanding how leaders shape people’s beliefs and actual pro-social behavior.

The framework for our analysis is the public goods game. We chose a public goods context because the real life problems that have inspired our research - tax morale, corruption, corporate culture etc. - have features of a public good. The public goods game gives players a selfish incentive to free ride, irrespective of their beliefs about how others will behave and irrespective of the fact that free riding is socially inefficient.

Our specific setup is as follows. Four players, who form a stable group for ten rounds, make contributions to a linear public good. Since we are interested in the link between beliefs and behavior we elicit beliefs of all players about how much others will contribute. We will look at belief effects in two basic variations of the public goods game. In one version (the

\footnotetext{
${ }^{1}$ We will discuss the relevant evidence in the next section.
} 
'leader treatment'), one randomly chosen player is assigned to be the 'leader' who decides first how much to contribute to the public good., ${ }^{2,3}$ The other players are 'followers' who decide simultaneously how much to contribute after they observe the leader's contribution. A leader-follower framework has the advantage that we can observe how the leader's action influences followers' beliefs. We contrast the leader treatment with a "no-leader treatment" in which all group members decide simultaneously. ${ }^{4}$

Our main results are as follows. Leaders strongly shape their followers' beliefs. In this sense, leaders are 'role models'. While this holds in all periods, it is particularly important in the first period. In later periods we find that the followers' beliefs in a given period are not only determined by what the leader did in the present period but also by what other followers did in the past. Moreover, when forming beliefs for the current period followers put more weight on average on the other followers' past behavior than on the leader's current behavior. This leads to a strong path dependency: the leader's initial behavior shapes the followers' initial behavior and in later periods the followers' behavior is not only determined by the leader's current contribution but also - and even more strongly- it is shaped by the other followers' past behavior. Thus, if a leader initially contributed little, then this will have a long-lasting effect on the beliefs of followers that is not easily corrected later on.

Path dependency effects also exist in the no-leader treatment. Groups that start at high contribution levels have on average higher overall contribution levels than groups that start out low. An explanation for this observation is that in teams with no leader beliefs are shaped initially by the group members' intuitive ('homegrown') beliefs and later on by the followers' past behavior. More importantly, contributions, for a given belief, are the same in both

\footnotetext{
${ }^{2}$ We deliberately selected the leader randomly and anonymously, because we did not want to confound leaderinduced belief effects with leader attributes, like status, persuasion, charisma, ability, superior information, power etc. These leader attributes certainly can matter strongly in reality. Our stripped-down leader-follower game measures only one aspect of leadership - leading by example. An investigation of other aspects of leadership or the impact of leader attributes requires different designs. For examples see Güth et al. (2007); Van Vugt and Ahuja (2010) and Arbak and Villeval (2013).

${ }^{3}$ We focus on the role of leaders for cooperation. Of course, leaders are also important for coordinating behavior. See Foss (2001) and Weber et al. (2001) on the role of leaders to solve coordination problems.

${ }^{4}$ As we will see below, we are in particular interested in how leaders shape beliefs and action at the beginning of the leader-follower relationship. In a standard public goods game, players decide simultaneously about how much to contribute initially and they can thereby only rely on their homegrown beliefs.
} 
treatments: the same belief triggers the same behavior. Yet, in the leader treatment it is in the hand of the leader to shape beliefs.

We make three contributions to the literature. First, our two treatments provide simple frameworks for understanding belief effects in reality: In some situations beliefs are shaped by role models such as politicians, top officials, managers, or even celebrities, whereas in other situations beliefs are influenced by the behavior of the relevant group members, in the absence of leaders. As we will show in the next section there is plenty of field evidence that is consistent with belief effects. Yet, causal inferences of beliefs on behavior are hardly feasible in the field. Our experimental approach allows the observation of beliefs and how leaders influence them. Thus, our experimental data provide a behavioral micro-foundation for field observations that are consistent with presumed belief effects. Our main insight is that there is strong path dependency in behavior in both treatments. In our view the observation of path dependency contributes to an explanation why it is so difficult to fight corruption, tax evasion, and welfare fraud and why corporate cultures are hard to change. Once a norm of cooperation is destroyed, leaders have a hard time re-establishing it because followers are more strongly impressed by their beliefs about other followers than about the leader's behavior.

Second, by comparing belief effects in games with and without a leader we contribute to a better understanding of determinants of voluntary cooperation. Existing experimental evidence (see next section) suggests that people contribute on average more the more they believe others contribute. This observation implies that any factor that shifts beliefs will shift behavior. Our leader-follower framework is suitable to test this implication because leaders are in a position to shift follower's beliefs.

Finally, while our paper is not the first in a 'leading-by-example' framework, it is the first to elicit leaders' and followers' beliefs about others' contributions. ${ }^{5}$ This allows us to

\footnotetext{
${ }^{5}$ Previous papers in a 'leading-by-example' framework comprise Gächter and Renner (2006); Moxnes and van der Heijden (2003); Güth et al. (2007); Potters et al. (2007); Gächter et al. (2012); Arbak and Villeval (2013) and Drouvelis and Nosenzo (2013). Also related is d'Adda et al. (2014), who study whether the ethical conduct of a leader has an impact on the ethical conduct of a group of followers. For a psychological account of leadership effects in social dilemma situations see Van Vugt and De Cremer (2002). None of these studies elicited beliefs.
} 
understand better how leading by example actually works and may thus contribute to further theory development. ${ }^{6}$

\section{The importance of beliefs for pro-social behavior - evidence from the field and the lab}

Here we discuss evidence from the field and the lab that has inspired our research. Our focus is on evidence that beliefs about others' behavior matter for pro-social behavior.

\subsection{Field (experimental) evidence}

Economically important areas where belief effects might be relevant are donations to charities, tax morale and abuse of the welfare state, corruption, criminal behavior, and corporate culture. We hasten to add that for all field examples discussed below belief effects are not the only factor that play a role; standard economic explanations like correlated and contextual effects (Manski (2000)) are certainly important as well.

With this caveat in mind, we start with charitable donations. In some fund-raising campaigns it is common practice to list the names and donated amount on fund raising websites. $^{7}$ Donations by well-known politicians and celebrities often feature prominently. This observation suggests that fund raising organizers not only rely on people's feelings of altruism and compassion but also on belief effects: the organizers apparently think that more people will donate if many others (and in particular prominent people) do so as well. Seed money effects (List and Lucking-Reiley (2002)) are a related phenomenon that at least in part exploits belief effects. ${ }^{8}$ Finally, consistent with belief effects, Andreoni and Scholz (1998) report econometric evidence that charitable donations depend to some degree on other people's donations.

Tax morale is another interesting case because taxes are typically used to finance public goods from which one benefits even if one has not paid taxes. Existing evidence suggests that, controlling for detection probabilities, people are less likely to cheat on their taxes or to

\footnotetext{
${ }^{6}$ Previous theoretical papers on leading by example comprise Bianco and Bates (1990), Hermalin (1998) and Arce (2001). However, while the above-cited experimental papers explain leading by example at least in part by non-selfish reciprocal motivations, these theoretical studies all give (different) rational (or evolutionary) accounts of leading by example under the selfishness assumption.

${ }^{7}$ See, for example, http://www.justgiving.com.

${ }^{8}$ There is also experimental evidence on leadership effects in charitable donations. See Andreoni and Petrie (2004) and Potters et al. (2005).
} 
commit benefit fraud if others behave honestly (e.g., Slemrod (1992); Andreoni et al. (1998); Scholz and Lubell (1998)). In line with this evidence Cowell (1990) argues: "a person's propensity to dodge taxes seems to be strongly affected by the number of other people who are already doing the same" (p. 108).

Frey and Torgler (2007) provide empirical evidence for the relevance of belief effects for tax morale. They use data from the European Values Survey and conduct a multivariate analysis across 30 countries. Controlling for a host of variables Frey and Torgler find a positive correlation between people's tax morale (measured by a question whether cheating on taxes is justified if you have the chance) and people's perception how many others cheat on taxes. ${ }^{9}$ Hallsworth et al. (2014) using a natural field experiment in the UK show that letters to people who still owe their taxes containing messages about a high number of compliant fellow citizens are particularly effective in inducing payments of tax liabilities. ${ }^{10}$

An interesting further observation is that tax morale in various countries is also affected significantly by the behavior of 'leaders' - recall the opening quotes. Further studies provide evidence that is consistent with this observation. Tax morale seems to be positively correlated with trust into the government (e.g., Scholz and Lubell (1998); Alm et al. (2006)) and trust in officials including a country's president (e.g., Torgler (2005)).

The cited studies look at tax morale measured by variables such as how justified it is to cheat on taxes. These studies do not investigate determinants of perceptions regarding how many other people cheat on taxes. The study by Hammar et al. (2009) is a notable exception. Their main finding is that distrust in politicians increases perceived tax evasion.

Belief effects may also matter for corruption, criminal behavior and public disorder. Corruption may be more prevalent the more people think other people are corrupt (Klitgaard (1988); Huang and Wu (1994)). Similarly, people are more likely to commit crimes if they think criminal behavior is widespread (Kahan (1997)). For instance, on the basis of data from forty US-American cities, Skogan (1990) shows a positive relationship between public disorder and criminal behavior. At a less dramatic scale, in an ingenious experiment

\footnotetext{
${ }^{9}$ This sort of evidence has also influenced theory development. Traxler (2010) provides a theoretical analysis of the implications of conditional cooperation for tax evasion. For an early theoretical treatment on the importance of perceived tax evasion see Bordignon (1993).

${ }^{10}$ As Hallsworth et al. (2014) also point out, details of wording seem to matter strongly becauseFellner et al. (2013) find limited evidence on the effectiveness of referring to a high number of compliant people.
} 
conducted on a parking lot, psychologists Cialdini et al. (1990) demonstrate that people are much more likely to throw away a flyer (attached to their cars by the experimenters) if the parking lot appears littered; if it is clean, people litter significantly less (see also Keizer et al. (2008)). The explanation is that people react sensitively to signals about what they believe is considered 'normal behavior' in a specific social setting.

While all these studies provide evidence that is consistent with the existence of belief effects for pro-social behavior, a drawback is that most data do not stem from controlled environments (with the exceptions of Cialdini et al. (1990) and Keizer et al. (2008)), which makes causal interpretations infeasible. We turn therefore to experimental evidence on the importance of beliefs for pro-social behavior.

\subsection{Experimental evidence}

Psychologists have long argued that people's cooperation behavior depends on what others do (e.g., Kelley and Stahelski (1970)). Many people are 'conditional cooperators' who cooperate if others cooperate and free ride if others free ride. Using the methodology of experimental economics Keser and van Winden (2000) were among the first economists to argue for the prevalence of conditional cooperation. Croson (2007) went one decisive step further by eliciting beliefs about other group members' contributions. She finds a very high and statistically significant correlation of beliefs and contributions: Subjects who expect others to contribute a lot are more likely to contribute high amounts than subjects who expect others to free ride. Neugebauer et al. (2009), Fischbacher and Gächter (2010); Gächter and Renner (2010); and Dufwenberg et al. (2011) also find a highly significantly positive relationship between beliefs and contributions. Finally, experiments with the 'strategy method', where people make contribution decisions for all possible average contribution level of other group members, find strong evidence for conditional cooperation. ${ }^{11}$

The behavioral relevance of conditional cooperation has also been shown in field experiments. For instance, in a field study on voluntary donations to social funds at the University of Zurich, Frey and Meier (2004) show that students who are informed that 64 percent of the other students contributed to the social funds are more likely to contribute than

\footnotetext{
${ }^{11}$ See e.g., Ockenfels (1999); Fischbacher et al. (2001); Falk and Fischbacher (2002); Muller et al. (2008); Kocher et al. (2008); Herrmann and Thöni (2009); Fischbacher and Gächter (2010); Thöni et al. (2012) and Volk et al. (2012). Chaudhuri (2011) provides a survey of this literature.
} 
students who are told that only 46 percent donated to the social funds. Meier (2006) replicates this finding in a follow-up study. ${ }^{12}$ Rustagi et al. (2010) study forest management groups in Ethiopia and find that groups comprising more conditional cooperators are also more successful in managing their forest commons.

\subsection{Discussion}

As shown, naturally occurring field evidence as well as lab and field experiments suggest that people contribute more to the public good the more they believe others contribute. It follows from this observation that any factor that shifts beliefs will shift behavior. Leaders, whose behavior is visible to followers, are in a particularly powerful position to influence their followers' beliefs. Therefore, we chose a leader-follower public goods game, which we detail in the next section, as one framework for our analysis. Since belief effects also matter in the absence of leaders, which characterizes many of the situations discussed above, we also look at belief effects in a public goods game without a leader.

\section{Design and procedures}

Our basic design involves a linear public goods game. Each of the four team members has to decide on how many of 20 tokens to keep and how many tokens to contribute to a team project. For simplicity, the size of the team project is just the sum of all contributions to it. The payoff for each subject is given by:

$$
\pi_{i}=20-g_{i}+0.4 \sum_{j=1}^{4} g_{j}
$$

From (1) it is obvious that a rational and selfish individual has an incentive to free ride on the other group member's contributions (i.e., to choose $g_{i}=0$ ). A social dilemma arises, since it is in the joint interest of the group to contribute the whole amount to the team project but individual incentives are to contribute nothing.

The leader game is a simple variation of this standard public goods game. One randomly selected group member who we will henceforth call the 'leader' decides first in his or her team. We selected the leader randomly, to avoid a confound with leader attributes (see footnote 2). The other three group members (called the 'followers') learn about the leader's

\footnotetext{
${ }^{12}$ See Croson and Shang (2008), Martin and Randal (2008), Alpizar et al. (2008) and Chen et al. (2010) for further examples and Gächter (2007) for a discussion.
} 
contribution to the team project and then decide simultaneously about their contributions to the team project. ${ }^{13}$ The payoff functions of all team members, including the leader's, are identical and equal to (1). The presence of a leader does not change incentives to free ride.

We have two treatments - a treatment with a leader (the 'leader treatment') and a control treatment with no leader in which group members decided simultaneously ('no-leader treatment'). The purpose of the leader treatment is to see to what extent a leader shapes both players' beliefs about how others play and their actual contributions. In both treatments the relevant game was repeated ten times. Teams remained the same throughout the experiment ('partners' design). A participant took part in one treatment only.

Since we are interested in belief effects, we elicited beliefs in each round of the game. Specifically, in the no-leader treatment we asked participants to estimate the average of the other players' contributions. In the leader treatment we asked the leader about his or her estimate how many tokens the three followers would contribute on average; each follower had to submit his or her estimate of the average contribution of the two other followers after having seen the leader's contribution.

We follow Gächter and Renner (2010) in how we incentivized belief elicitation. We paid subjects 20 money units in every case where a participant estimated the actual contribution of others exactly right ( \pm 0.5 tokens); and 10 money units/(absolute) estimation error if their estimate deviated by more than \pm 0.5 tokens from the actual contribution.

We conducted all experiments with z-Tree (Fischbacher (2007)) in the laboratory at the University of Erfurt (eLab). Our participants were 96 undergraduates from various disciplines; 48 participated in the leader treatment and 48 in the no-leader treatment. In total we have thus observations from 24 independent groups of four subjects.

The participants were randomly assigned to the booths in the laboratory at the beginning of each session. The booths separated the participants visually and ensured that every individual made his or her decision anonymously and independently. The written instructions explained the above social dilemma situation and the experimental procedures. We assigned the groups randomly and anonymously, such that participants did not know which of the other participants were in their group. Participants had to answer a set of control questions to ensure

\footnotetext{
${ }^{13}$ In the experiment we never talked of leaders and followers, but instead of the participant that decides first in his or her group. See the instructions in the appendix for further details.
} 
that every participant understood the decision problem. We did not start the experiment before all participants had answered all control questions correctly. Subjects were paid anonymously in cash immediately after each session. Our experiments lasted 30 minutes on average, and participants earned €6.00.

\section{Results}

\subsection{Determinants of beliefs}

We start with the impact of the leaders' decision on followers' beliefs. Fig. 1 records our main finding. The $x$-axis depicts the leaders' contribution and the $y$-axis records the followers' average belief or contribution, respectively. We distinguish between periods. All effects we report in the following paragraphs are significant at $\mathrm{p}<0.01$, according to Spearman rank order correlations with independent group averages as observations.

The left panel shows the first period in which the followers have not yet observed any follower decisions. Leaders in the first period contributed 5, 10, 12, 15 or 20 tokens. Higher leader contributions trigger higher beliefs of followers about the other follower's contributions. Moreover, on average followers very closely match their beliefs with their actual contributions. Thus, leaders shape the belief of followers and appear to be role models for them.
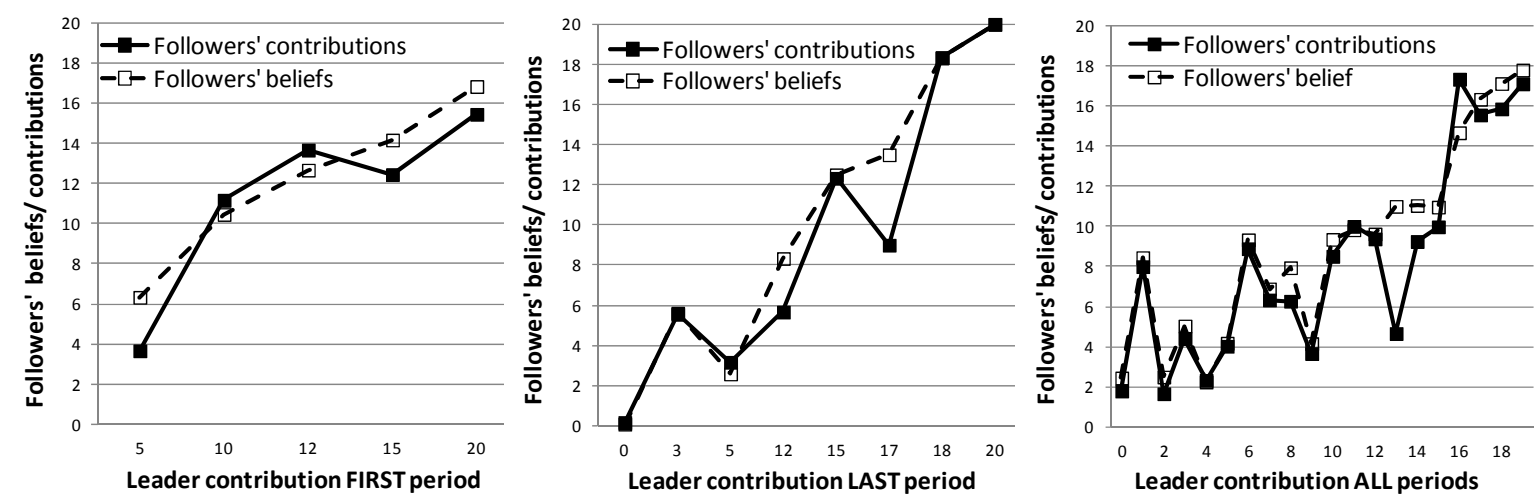

Fig. 1. Leaders as role models: Followers' beliefs and contributions as a function of the leader's contribution in the first period (left), last period (middle) and over all periods (right).

The middle panel looks at the tenth period. This period is interesting, because it is the last one and hence there is no strategic reason to match the leader's contribution. Yet, we observe that the followers' beliefs about other followers' contributions increase highly significantly in the leaders' contributions. The followers also match their beliefs; that is, followers are 
conditional cooperators on average. This result is consistent with previous findings on conditional cooperation.

The final panel records the evidence over all periods. We find that both the followers' beliefs and contributions are positively correlated with the leader's contributions.

Table 1 investigates the determinants of beliefs econometrically. We use OLS and calculate robust standard errors using the group as the independent clustering unit (this assumes that decisions are correlated within a group but independent across groups). Specifically, we estimate a belief formation model as developed by Fischbacher and Gächter (2010) in the context of a ten times repeated public good experiment with random matching. ${ }^{14}$ Fischbacher and Gächter show that a subject's belief in period $t$ about the other group members' average contribution in period $t$ can be described as a weighted average of the belief a subject held in period $t-1$ and what the other group members actually contributed on average in period $t-1$.

\section{Table 1}

Determinants of beliefs in the absence and presence of a leader

\begin{tabular}{|c|c|c|}
\hline & No-leader treatment & Leader treatment \\
\hline & $\begin{array}{l}\text { Beliefs about other group } \\
\text { members' contribution in } t\end{array}$ & $\begin{array}{l}\text { Beliefs of followers about } \\
\text { other follower's contribution in } t\end{array}$ \\
\hline Leader contribution in $t$ & & $\begin{array}{c}0.373^{* * *} \\
(0.090)\end{array}$ \\
\hline Own belief in $t-1$ & $\begin{array}{c}0.329 * * * \\
(0.067)\end{array}$ & $\begin{array}{c}0.087 * * * \\
(0.028)\end{array}$ \\
\hline Average contribution of others in $t-1$ & $\begin{array}{c}0.629 * * * \\
(0.058)\end{array}$ & $\begin{array}{c}0.519 * * * \\
(0.074)\end{array}$ \\
\hline Constant & $\begin{array}{c}0.461 \\
(0.325)\end{array}$ & $\begin{array}{c}0.010 \\
(0.604)\end{array}$ \\
\hline Observations & 432 & 432 \\
\hline R-squared & 0.82 & 0.86 \\
\hline
\end{tabular}

OLS; robust standard errors in parentheses; *** significant at $1 \%$

The first model in Table 1 presents the results of this belief formation model in our data set of the no-leader treatment. Like Fischbacher and Gächter (2010) we find that beliefs in

\footnotetext{
${ }^{14}$ Fischbacher and Gächter (2010) also had groups of four subjects and the same payoff function (1) as the present experiment. See their paper for further details on the belief formation model and Smith (2013) for a general analysis of belief effects in public goods.
} 
period $t$ are a weighted average of own beliefs in period $t-1$ and average actual contributions of others in period $t-1$. $^{15}$ When forming their estimates about the likely contributions of others, subjects put about a weight of one third on their own previous belief and a weight of two thirds on the observed average contribution of others in the previous period.

In the leader treatment contributions can be shaped by the leader's current contribution, the followers' previous contributions, and the follower's beliefs in $t-1$ about others' contributions. The estimation results show again that beliefs are a weighted average of all three variables, which are all highly significant. ${ }^{16}$ In the presence of a leader the importance of own beliefs in $t-1$ is largely diminished (although still highly significant). The important variables are the leader's contribution and the other followers' past contributions. An increase of a leader's contribution by one token increases the followers' average belief by 0.373 tokens. The impact of others' average contribution on follower beliefs is substantially higher: a one token increase in others' average contribution in $t-1$ increases the followers' average belief by 0.519 tokens. In this sense the followers' past contributions are more important for the beliefs about the likely behavior of other followers in the current period than the leader's contribution in the current period.

The observation that the other followers' past behavior is more important for beliefs than the leader's current behavior leads to a 'path dependency effect'. From Fig. 1 we know that the leader's contribution shapes the followers' initial beliefs and actual contributions very strongly. Yet, in subsequent periods the followers' belief of what happens in the current period depends more strongly on what the other followers have done in the past than what the leader just did in the present period. Thus, the direct contemporaneous impact of the leader is diminished relative to the weight that followers attach to the other followers' past behavior when forming their beliefs about the likely behavior of other followers in the present period. In other words, the impact of a leader's contribution is strongest in the first period and, while playing a role in subsequent periods, it is not strong enough to correct the beliefs of followers once they can observe the actual contributions of followers in the later periods.

\footnotetext{
${ }^{15}$ An F-test does not allow rejecting the null hypotheses that the sum of coefficients "Own beliefs in $t-1$ " and “Others' average contributions in $t-1$ ” is one $(\mathrm{p}=0.13)$.

${ }^{16}$ An F-test confirms that the sum of coefficients is insignificantly different from unity $(\mathrm{p}=0.51)$.
} 


\subsection{The link between beliefs and contributions}

Our next step is to understand how beliefs in period $t$ and contributions in period $t$ are linked. Fig. 2 documents the results. On the $x$-axis we depict the belief about others' contributions and on the $y$-axis we show the average actual contribution. We distinguish between the two treatments. We find strong evidence for conditional cooperation in both treatments. Moreover, average contribution behavior conditional on given beliefs is virtually identical between treatments. Thus, the presence of a leader has not altered conditionally cooperative behavior in any substantial sense. A further interesting observation is that in both treatments players match their beliefs almost perfectly with their contributions. Moreover, beliefs and contributions follow the diagonal very closely.

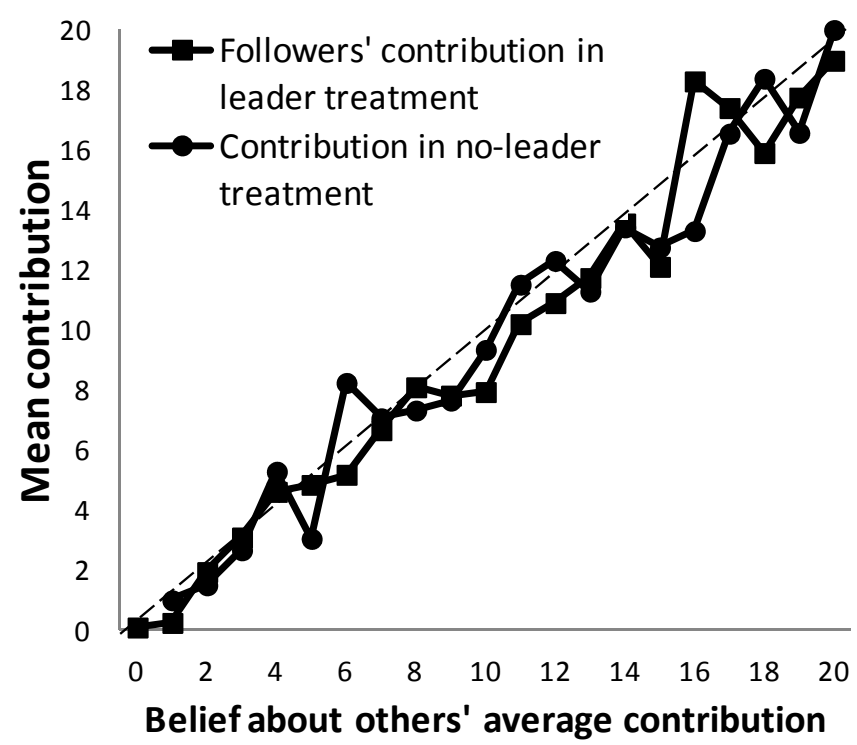

Fig. 2. Contributions as a function of the beliefs about other group members' contribution in games with and without a leader.

Table 2 investigates the link between contributions and beliefs econometrically. We distinguish between the no-leader treatment and the leader treatment. For both treatments we run two OLS regression models with robust standard errors on independent groups.

In the first model (columns (1) and (3)) we only include the belief about others' average contribution in period $t$ as a regressor. We find that in both treatments the estimated coefficients assume almost unity and are highly significant.

In our second set of models (columns (2) and (4)) we include the own contribution in $t-1$ as an explanatory variable. The reason is that people might follow an idiosyncratic contribution pattern, which we capture by this variable. We find in both models that this 
variable matters strongly both in terms of size and significance. An interesting observation is that the belief about others' average contribution matters somewhat more in the leader treatment than in the no-leader treatment; for the variable 'own contribution in $t-1$ ' the opposite conclusion holds.

\section{Table 2}

Cooperation in the presence and absence of a leader

\begin{tabular}{|c|c|c|c|c|}
\hline \multirow{3}{*}{ Dependent variable: } & \multicolumn{2}{|c|}{ No-leader treatment } & \multicolumn{2}{|c|}{ Leader treatment } \\
\hline & \multicolumn{2}{|c|}{ Contribution } & \multicolumn{2}{|c|}{ Follower contribution } \\
\hline & $(1)$ & $(2)$ & (3) & $(4)$ \\
\hline Belief about others' average contribution in $t$ & $\begin{array}{c}0.887 * * * \\
(0.068)\end{array}$ & $\begin{array}{c}0.494 * * * \\
(0.087)\end{array}$ & $\begin{array}{c}0.918 * * * \\
(0.072)\end{array}$ & $\begin{array}{c}0.641 * * * \\
(0.122)\end{array}$ \\
\hline Own contribution in $t-1$ & & $\begin{array}{c}0.523^{* * *} \\
(0.080)\end{array}$ & & $\begin{array}{c}0.361^{* * *} \\
(0.091)\end{array}$ \\
\hline Constant & $\begin{array}{c}0.738 \\
(0.787) \\
\end{array}$ & $\begin{array}{c}-0.571 \\
(0.327)\end{array}$ & $\begin{array}{c}0.054 \\
(0.574) \\
\end{array}$ & $\begin{array}{c}-0.707 \\
(0.231)\end{array}$ \\
\hline Observations & 480 & 432 & 360 & 324 \\
\hline R-squared & 0.40 & 0.57 & 0.59 & 0.67 \\
\hline
\end{tabular}

OLS; robust standard errors in parentheses; ${ }^{* * *}$ significant at $1 \%$

In section 4.1 we established a strong path dependency for beliefs. The strong relationship between beliefs and contributions implies a strong path dependency not only for contributions in the leader treatment but also in the no-leader treatment because beliefs on others' average contribution matter strongly in this treatment as well. Fig. 3 illustrates this path dependency at the group level. Each data point in Fig. 3 is an independent group of four members. We depict on the $x$-axis the mean contribution in period 1. On the $y$-axis we show the mean contribution of an independent group for the rest of the periods.

We see that in both the no-leader and the leader treatment period 1 group average contributions are significantly positively correlated with group average contributions for periods 2 to 10. The slope of the trend line is almost unity in both treatments. The betweengroup variance is higher in the leader treatment than in the no-leader treatment (compare the $\left.\mathrm{R}^{2} \mathrm{~s}\right)$.

In period 1 of the no-leader treatment contributions were determined by group members' beliefs about others' average contributions, without any information how other group members decided. In the leader treatment the leader's contribution shaped the mean 
contribution in period 1 (see Fig. 1). Thus, the main difference between treatments is that it is on average largely in the hand of the leader to determine the fate of his or her group in the leader treatment.
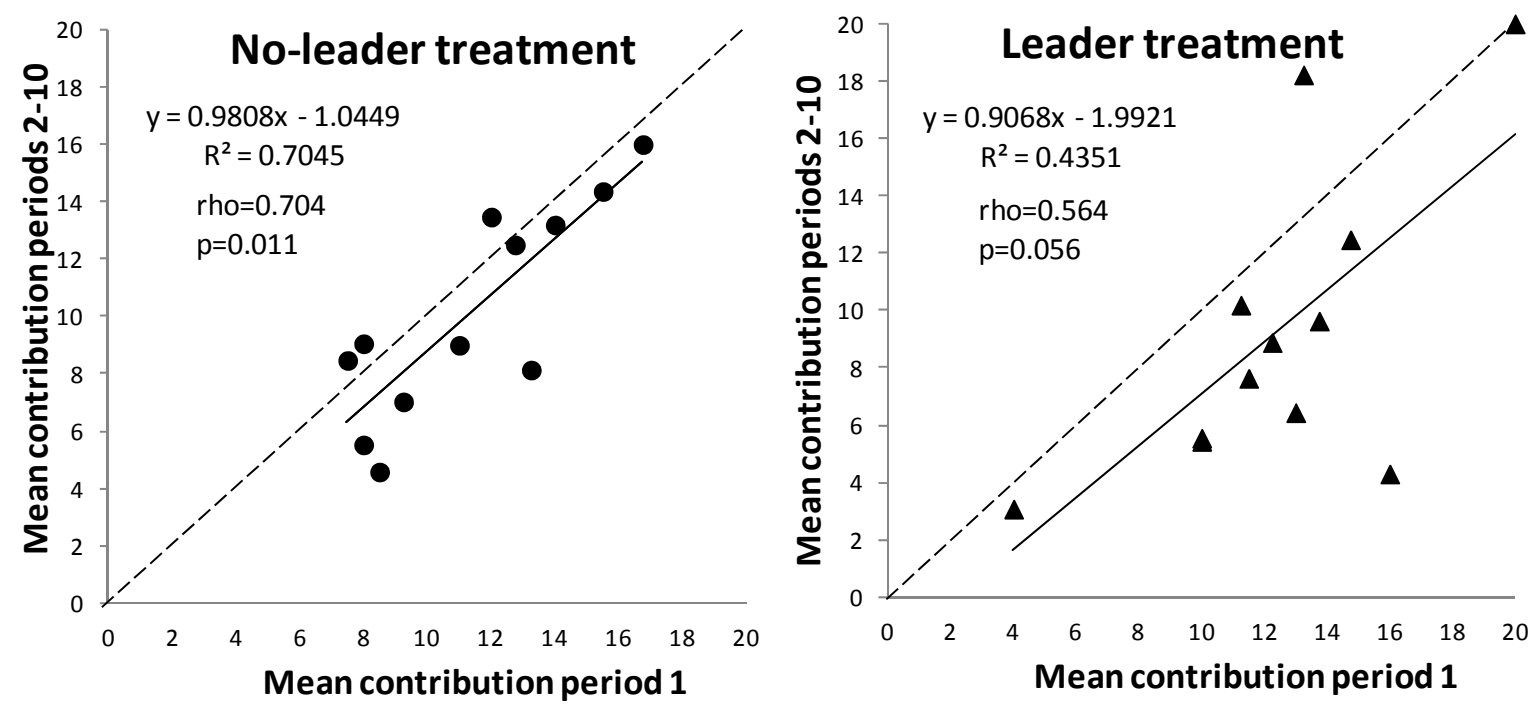

Fig. 3. The impact of a group's first-period contribution on the group cooperation level in the remaining periods in the absence (left) and presence of a leader (right).

\subsection{Can leaders increase contribution levels?}

Given these results a natural question to ask is whether leaders are able to lead their groups to higher cooperation levels than groups without a leader. To put the question differently: are leaders able to prevent the decline of cooperation that typically afflicts groups when contributions to the public good are determined simultaneously (Fischbacher and Gächter (2010))? The results so far make it plausible that this might be the case: leading by example works in the sense that leaders are able to shape the initial contributions and beliefs of their team members (see Fig. 1 and Table 1) and there is a very strong correlation between beliefs and contributions (Fig. 2 and Table 2). Thus, leaders should be able to lead their groups to higher contribution levels than those achieved by groups without a leader. Yet, our experiments suggest that the presence of a leader is of no avail.

Fig. 4 illustrates this sobering result. The left-hand panel shows the results in the leader treatment. We distinguish between beliefs and actual contributions and depict these variables for both leaders and followers. Followers contribute slightly less than what they believe other followers will contribute (the difference is 0.77 tokens on average). Followers free ride even 
more on the leader's contribution by contributing on average difference 1.63 tokens less than the leader.

There is an interesting difference between leaders and followers: leaders contribute the amount they believe the followers will contribute, or even more (in particular towards the end). By contrast, followers' contributions fall short of their beliefs in almost all periods. This constitutes the 'leader's curse': leaders are 'suckers'. Apparently leaders alleviate the adverse feeling of being suckered by withdrawing their contributions over time. This explains why a comparison of group average contributions in the no-leader treatment (10.24) and the leadertreatment (9.64) shows no significant difference (Mann-Whitney test, group averages over all periods as observations, $\mathrm{p}=0.603$ ). Leaders do not lead their groups to higher contribution levels than those achieved by groups with no leaders. ${ }^{17}$
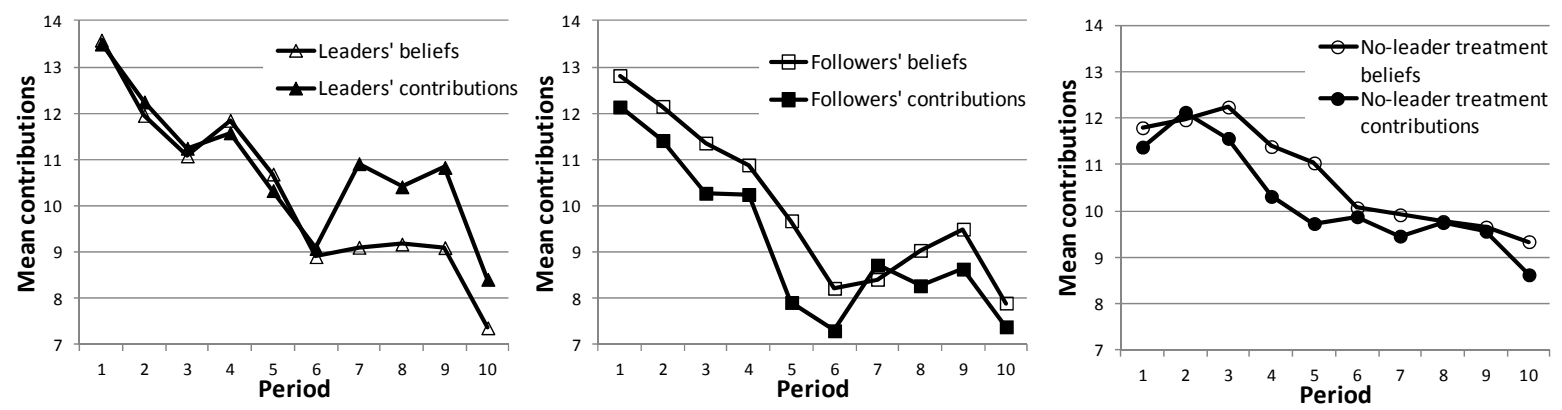

Fig. 4. The leader's curse.

The right-hand panel of Fig. 4 shows the mean beliefs about others' average contributions and the average actual contributions in the no-leader treatment. Beliefs follow contributions closely, although actual contributions fall slightly below expected contributions. There is a downward trend in both variables, which is expected given previous results (see Neugebauer et al. (2009), Fischbacher and Gächter (2010) and Bayer et al. (2013) for recent analyses).

\section{Summary and concluding discussion}

In this paper we analyzed the role of beliefs about other's behavior for own pro-social behavior. There is plenty of anecdotal and scientific evidence from the field and the lab that suggests a link between beliefs and pro-social behavior. If people's pro-social behavior is

\footnotetext{
${ }^{17}$ We analyze the 'leader’s curse' in a series of experiments in a companion paper (Gächter and Renner (2006)).
} 
belief-dependent, any factor that shifts people's beliefs will shift their behavior. In this paper we looked at 'leading by example' as a potentially strong belief-shifting factor and compared it to a setup without a leader (our 'no-leader treatment').

Our most important results are as follows. In both treatments we find strong belief effects: the higher the belief is the higher are contributions. Moreover, for a given belief contributions are identical between treatments. We find strong path dependency effects in both treatments: groups that start at high (low) cooperation maintain high (low) cooperation. In our no-leader treatment beliefs and contributions only depend on other group member's past contributions. In the leader treatment leading by example works in the sense that leaders shape the followers' initial contributions very strongly, but from then on followers, in forming their beliefs (and deciding on their contributions) put more weight on the other followers' past behavior than on the leader's current one. This observation implies that the leader's initial behavior has long-lasting effects. Finally, we found evidence for a 'leader's curse': although followers follow the leader's example and contribute more the more the leader contributes, the leader is nevertheless the 'sucker' in this game. As a consequence, leaders reduce their contributions over time, and cooperation collapses, much like in the no-leader treatment.

We conclude our paper by discussing a few implications of our results for understanding issues in public policy and management. We begin with our last result, the 'leader's curse'. Our findings suggest that good leaders need to be 'thick-skinned' and accept being 'exploited'. Put differently, good leaders need to resist the temptation to give in if their followers do not play ball to the extent the leader does. Second, since leaders are role models, the behavior of politicians, top officials and managers may matter strongly for the morale of citizens and employees. Thus, our findings from tightly controlled laboratory experiments underscore the observations made in our introductory quotes and the field evidence we discussed in Section 2. An interesting new insight of our laboratory approach is that there is a 'multiplier effect', because a bad example (dishonesty in tax matters, corruption, and unethical behavior in other domains) may not only have direct effects on a follower but may also trigger belief effects about how others will react. The path-dependency effect may affect morale adversely in the long-run. Leaders should thus be role models for whom higher moral standards should hold than for normal citizens.

An implication of our path dependency result is that leaders have the greatest direct impact of influencing their followers' behavior at the beginning of a relationship (see Figs. 1 
and 2). The fact that later on the impact of leaders on followers' beliefs is diminished may explain why in reality corporate cultures are hard to change or why tax evasion and corruption are hard to fight.

In our view the behavioral relevance of our findings extends beyond leadership by specific individuals. Belief management happens not only through leaders, but also through effects like the perceived fairness of the tax system, fair treatment by authorities, and democratic participation rights. For instance, there is evidence that the perception of the fairness of the tax system and the treatment by authorities matter for tax morale (Seidl and Traub (2001); Pommerehne and Weck-Hannemann (1996); Goette and Kucher (1998); Scholz and Lubell (1998); Feld and Frey (2002)). More generally, tax morale is significantly positively correlated with trust in the parliament and the justice system (e.g., Alm et al. (2006); Frey and Torgler (2007)). Similarly, tax morale is positively affected by various governance variables, like political stability, government effectiveness, rule of law, voice and accountability, regulatory quality and control of corruption (Frey and Torgler (2007)). A further interesting observation is that tax evasion at the Swiss cantonal level is lower in cantons where citizens have more direct democratic rights (e.g., Feld and Frey (2002); Torgler and Schaltegger (2005)).

How can our observations explain such findings? First, with regard to tax morale (similar conclusions may hold for the abuse of the welfare state and corruption), there may be a direct effect by the concerned individual who may reciprocate unfair treatment by authorities and/or the tax system by lower tax morale, simply because the taxpayer resents unfair treatment (Smith (1992)). Second, there may be an indirect effect of tax authorities (and the government in general), via the beliefs on other tax payers' behavior. The reason is that if many people share similar feelings and experiences, this will lower the belief that others have a high tax morale, which further undermines tax morale. Similarly, the government's trust in the honesty of its citizens may lead to a direct effect of "trust breeds trust" (Feld and Frey (2002)), presumably because people like to be considered trustworthy. Again, if such feelings are widespread, they may shape beliefs about other citizen's tax morale and hence reinforce the tax payer's morale. Direct-democratic procedures may influence tax morale positively because direct democracy may affect the beliefs about other people's tax morale once a tax law is passed in a referendum. A referendum signals people’s opinion about a topic and the 
dissemination of opinions via the result of a referendum may shape people's beliefs about others' behavior (Feld and Tyran (2002)).

Previous research (see Section 2) has focused primarily on the direct reciprocity effects mentioned above; indirect effects (via beliefs) are understudied. Put differently, there is only little evidence on how governments, politicians, and authorities influence people's perceptions on how pro-socially their fellow citizens will behave. We are only aware of one study, by Hammar et al. (2009), that investigated indirect effects by looking at the impact of trust in politicians on people's perceptions of tax morale. In conclusion, our results encourage further investigations of belief effects in economically interesting field data.

\section{Acknowledgements}

Support under ERC-AdG 295707 COOPERATION and under the ESRC Network on Integrated Behavioural Science (NIBS) is gratefully acknowledged. We are also grateful to the University of Erfurt for logistic and financial support. We received helpful comments from various seminar and conference audiences, Benjamin Beranek, Martin Sefton, Christian Thöni, Christian Traxler, and Marie-Claire Villeval.

\section{References}

Alm, J., Martinez-Vazquez, J., Torgler, B., 2006. Russian Attitudes Toward Paying Taxes Before, During, and After the Transition. International Journal of Social Economics 33, 832857.

Alpizar, F., Carlsson, F., Johansson-Stenman, O., 2008. Anonymity, reciprocity, and conformity: Evidence from voluntary contributions to a national park in Costa Rica. Journal of Public Economics 92, 1047-1060.

Andreoni, J., Erard, B., Feinstein, J., 1998. Tax compliance. Journal of Economic Literature 36, 818-860.

Andreoni, J., Petrie, R., 2004. Public goods experiments without confidentiality: a glimpse into fund-raising. Journal of Public Economics 88, 1605-1623.

Andreoni, J., Scholz, J.K., 1998. An econometric analysis of charitable giving with interdependent preferences. Economic Inquiry 36, 410-428.

Arbak, E., Villeval, M.C., 2013. Voluntary leadership: motivation and influence. Social Choice and Welfare 40, 635-662. 
Arce, D., G., 2001. Leadership and the aggregation of international collective action. Oxford Economic Papers 53, 114-137.

Bayer, R.-C., Renner, E., Sausgruber, R., 2013. Confusion and learning in the voluntary contributions game. Experimental Economics 16, 478-496.

Bianco, W.T., Bates, R.H., 1990. Cooperation by Design: Leadership, Structure, and Collective Dilemmas. The American Political Science Review 84, 133-147.

Bordignon, M., 1993. A fairness approach to income tax evasion. Journal of Public Economics 52, 345-362.

Chaudhuri, A., 2011. Sustaining cooperation in laboratory public goods experiments: a selective survey of the literature. Experimental Economics 14, 47-83.

Chen, Y., Harper, F.M., Konstan, J., Li, S.X., 2010. Social Comparisons and Contributions to Online Communities: A Field Experiment on MovieLens. Journal Article 100, 1358-1398.

Cialdini, R.B., Reno, R., Kallgren, C., 1990. A focus theory of normative conduct: Recycling the concept of norms to reduce littering in public places. Journal of Personality and Social Psychology 58, 1015-1026.

Cowell, F.A., 1990. Cheating the Government: The Economics of Evasion. The MIT Press, Cambridge, Mass.

Croson, R., 2007. Theories of commitment, altruism and reciprocity: evidence from linear public goods games. Economic Inquiry 45, 199-216.

Croson, R., Shang, J., 2008. The impact of downward social information on contribution decisions. Experimental Economics 11, 221-233.

d'Adda, G., Darai, D., Weber, R.A., 2014. Do Leaders Affect Ethical Conduct? CESifo Working Paper No. 4913.

Drouvelis, M., Nosenzo, D., 2013. Group identity and leading-by-example. Journal of Economic Psychology 39, 414-425.

Dufwenberg, M., Gächter, S., Hennig-Schmidt, H., 2011. The framing of games and the psychology of play. Games and Economic Behavior 73, 459-478.

Falk, A., Fischbacher, U., 2002. "Crime" in the lab-detecting social interaction. European Economic Review 46, 859-869.

Feld, L., Frey, B.S., 2002. Trust breeds trust: How taxpayers are treated. Economics of Governance 3, 87-99.

Feld, L.P., Tyran, J.-R., 2002. Tax Evasion and Voting: An Experimental Analysis. Kyklos 55, 197-221.

Fellner, G., Sausgruber, R., Traxler, C., 2013. Testing enforcement strategies in the field: Threat, moral appeal and social information. Journal of the European Economic Association 11, 634-660.

Fischbacher, U., 2007. z-Tree: Zurich toolbox for readymade economic experiments. Experimental Economics 10, 171-178. 
Fischbacher, U., Gächter, S., 2010. Social preferences, beliefs, and the dynamics of free riding in public good experiments. Journal Article 100, 541-556.

Fischbacher, U., Gächter, S., Fehr, E., 2001. Are people conditionally cooperative? Evidence from a public goods experiment. Economics Letters 71, 397-404.

Foss, N.J., 2001. Leadership, Beliefs and Coordination: An Explorative Discussion. Industrial and Corporate Change 10, 357-388.

Frey, B.S., Meier, S., 2004. Social comparisons and pro-social behavior. Testing 'conditional cooperation' in a field experiment. Journal Article 94, 1717-1722.

Frey, B.S., Torgler, B., 2007. Tax morale and conditional cooperation. Journal of Comparative Economics 35, 136-159.

Gächter, S., 2007. Conditional cooperation: Behavioral regularities from the lab and the field and their policy implications, in: Frey, B.S., Stutzer, A. (Eds.), Psychology and Economics: A Promising New Cross-Disciplinary Field (CESifo Seminar Series). The MIT Press, Cambridge, pp. 19-50.

Gächter, S., Nosenzo, D., Renner, E., Sefton, M., 2012. Who makes a good leader? Cooperativeness, optimism, and leading-by-example. Economic Inquiry 50, 953-967.

Gächter, S., Renner, E., 2006. The Leader's Curse. in preparation No.

Gächter, S., Renner, E., 2010. The effects of (incentivized) belief elicitation in public goods experiments. Experimental Economics 13, 364-377.

Goette, L., Kucher, M., 1998. Trust Me. An empirical analysis of taxpayer honesty. Finanzarchiv 55, 429-444.

Güth, W., Levati, M.V., Sutter, M., Van der Heijden, E., 2007. Leading by example with and without exclusion power in voluntary contribution experiments. Journal of Public Economics 91, 1023-1042.

Hallsworth, M., List, J.A., Metcalfe, R.D., Vlaev, I., 2014. The behavioralist as tax collector: using natural field experiments to enhance tax compliance. NBER Working Paper No. 20007.

Hammar, H., Jagers, S.C., Nordblom, K., 2009. Perceived tax evasion and the importance of trust. Journal of Socio-Economics 38, 238-245.

Hermalin, B.E., 1998. Toward an Economic Theory of Leadership: Leading by Example. Journal Article 88, 1188-1206.

Herrmann, B., Thöni, C., 2009. Measuring conditional cooperation: a replication study in Russia. Experimental Economics 12, 87-92.

Huang, P., Wu, H.-M., 1994. More order without more law: A theory of social norms and organizational cultures. Journal of Law, Economics \& Organization 10, 390-406.

Kahan, D., 1997. Social Influence, Social Meaning, and Deterrence. Virginia Law Review 83, 349-395.

Keizer, K., Lindenberg, S., Steg, L., 2008. The Spreading of Disorder. Science 322, 16811685. 
Kelley, H., Stahelski, A., 1970. Social interaction basis of cooperators' and competitors' beliefs about others. Journal of Personality and Social Psychology 16, 190-219.

Keser, C., van Winden, F., 2000. Conditional cooperation and voluntary contributions to public goods. Scandinavian Journal of Economics 102, 23-39.

Klitgaard, R., 1988. Controlling Corruption. University of California Press, Los Angeles.

Kocher, M.G., Cherry, T., Kroll, S., Netzer, R.J., Sutter, M., 2008. Conditional cooperation on three continents. Economics Letters 101, 175-178.

List, J., Lucking-Reiley, D., 2002. The effects of seed money and refunds on charitable giving: Experimental evidence from a university capital campaign. Journal of Political Economy 110, 215-233.

Manski, C.F., 2000. Economic Analysis of Social Interactions. Journal of Economic Perspectives 13, 115-136.

Martin, R., Randal, J., 2008. How is donation behaviour affected by the donations of others? Journal of Economic Behavior \& Organization 67, 228-238.

Meier, S., 2006. Does Framing Matter for Conditional Cooperation? Evidence from a Natural Field Experiment. Contributions to Economic Analysis \& Policy 5, Article 1, available at: http://www.bepress.com/bejeap/contributions/vol5/iss2/art1.

Moxnes, E., van der Heijden, E., 2003. The Effect of Leadership in a Public Bad Experiment. Journal of Conflict Resolution 47, 773-795.

Muller, L., Sefton, M., Steinberg, R., Vesterlund, L., 2008. Strategic behavior and learning in repeated voluntary-contribution experiments. Journal of Economic Behavior \& Organization 67, 782-793.

Neugebauer, T., Perote, J., Schmidt, U., Loos, M., 2009. Self-biased conditional cooperation: On the decline of cooperation in repeated public goods experiments. Journal of Economic Psychology 30, 52-60.

Ockenfels, A., 1999. Fairness, Reziprozität und Eigennutz - ökonomische Theorie und experimentelle Evidenz. Mohr Siebeck, Tübingen.

Pommerehne, W.W., Weck-Hannemann, H., 1996. Tax rates, tax administration and income tax evasion in Switzerland. Public Choice 88, 161-170.

Potters, J., Sefton, M., Vesterlund, L., 2005. After you--endogenous sequencing in voluntary contribution games. Journal of Public Economics 89, 1399-1419.

Potters, J., Sefton, M., Vesterlund, L., 2007. Leading-by-example and signaling in voluntary contribution games: an experimental study. Economic Theory 33, 169-182.

Rustagi, D., Engel, S., Kosfeld, M., 2010. Conditional Cooperation and Costly Monitoring Explain Success in Forest Commons Management. Science 330, 961-965.

Scholz, J.T., Lubell, M., 1998. Trust and Taxpaying: Testing the Heuristic Approach to Collective Action. American Journal of Political Science 42, 398-417.

Seidl, C., Traub, S., 2001. Taxpayers' attitudes, behavior, and perception of fairness. Pacific Economic Review 6, 255-267. 
Skogan, W.G., 1990. Disorder and Decline: Crime and the Spiral of Decay in American Neighborhoods. University of California Press, Berkeley.

Slemrod, J., 1992. Why People Pay Taxes: Tax Compliance and Enforcement. University of Michigan Press, Ann Arbor.

Smith, A., 2013. Estimating the causal effect of beliefs on contributions in repeated public good games. Experimental Economics 16, 414-425.

Smith, K.W., 1992. Reciprocity and fairness: Positive incentives for tax compliance, in: Slemrod, J. (Ed.), Why People Pay Taxes: Tax Compliance and Enforcement. University of Michigan Press, Ann Arbor.

Thöni, C., Tyran, J.-R., Wengström, E., 2012. Microfoundations of social capital. Journal of Public Economics 96, 635-643.

Torgler, B., 2005. Tax Morale in Latin America. Public Choice 122, 133-157.

Torgler, B., Schaltegger, C., 2005. Tax amnesties and political participation. Public Finance Review 33, 403-431.

Traxler, C., 2010. Social norms and conditional cooperative taxpayers. European Journal of Political Economy 26, 89-103.

Van Vugt, M., Ahuja, A., 2010. Selected: Why some people lead, why others follow, and why it matters: What Evolutionary Psychology Tells Us About Leadership and What Makes an Outstanding Leader. Profile Books, London.

Van Vugt, M., De Cremer, D., 2002. Leadership and cooperation in groups: Integrating the social dilemma and social identity perspectives. European Review of Social Psychology 13, 155-184.

Volk, S., Thöni, C., Ruigrok, W., 2012. Temporal stability and psychological foundations of cooperation preferences. Journal of Economic Behavior \& Organization 81, 664-676.

Weber, R., Camerer, C.F., Rottenstreich, Y., Knez, M., 2001. The illusion of leadership: Misattribution of cause in coordination games. Organization Science 12, 582-598. 


\section{Appendix: Instructions (online only)}

The instructions were originally written in German. We report the instructions of the leader treatment.

\section{General Information on the Experiment}

You are taking part in an experiment on decision-making. If you read the following instructions carefully, you can, depending on your decisions, earn a considerable amount of money. It is therefore very important that you understand the following instructions.

\section{- Earnings}

In the experiment you earn points. The points you have earned will be converted in Euros at the rate

$$
1 \text { point }=0.02 € \text {. }
$$

At the end of the experiment your total income in Euros will be paid to you in cash.

\section{- Group membership and anonymity}

During the experiment you are member of a group of four participants, i.e. there will be three more members in your group. The composition of the group will be the same during the whole experiment. Thus you form a group with the same participants throughout the experiment. It will be randomly determined with whom of the other participants you will form a group.

All participants decide anonymously, i.e. no participant will ever learn the identity of the other members of his group. To ensure anonymity it is imperative that all participants observe the following rule:

During the experiment all communication is prohibited, i.e. you are not allowed to speak or otherwise express yourself.

Should you have any questions please ask the experimenter.

\section{The Experimental Procedures}

The experiment consists of several periods.

\section{The decision situation in period 1-10}

The procedure is the same for each of these periods 1-10. Every participant receives $\mathbf{2 0}$ tokens at the beginning of each period. Your task is to decide how you use your endowment. You have to decide how many of the 20 tokens you want to contribute to a project and how many of them to keep for yourself.

\section{The calculation of your income}

Your income consists of two parts:

1) The tokens which you have kept for yourself ("Income from tokens kept”) whereby 1 token $=1$ point.

2) The income from the project. This income is calculated as follows:

Your income from the project $=0.4 \mathrm{x}$ the total contribution of all 4 group members to the project

Your income in points is therefore:

(20 - your contribution to the project) $+0.4 *$ (total contributions of all 4 group members to the project)

The income of each group member from the project is calculated in the same way, this means that each group member receives the same income from the project. 


\section{Examples:}

Suppose the sum of the contributions of all group members is 60 tokens. In this case each member of the group receives an income from the project of: $0.4 * 60=24$ points.

If the total contribution to the project is 9 tokens, then each member of the group receives an income of $0.4 * 9=$ 3.6 points from the project.

For each token, which you keep for yourself you earn an income of 1 point. Suppose you contributed this token to the project instead, then the total contribution to the project would rise by one point. Your income from the project would rise by $0.4 * 1=0.4$ points. However the income of the other group members would also rise by 0.4 points each, so that the total income of the group from the project would rise by 1.6 points. Your contribution to the project therefore also raises the income of the other group members. On the other hand you earn an income for each point contributed by the other members to the project. For each point contributed by any member you earn $0.4 * 1=0.4$ points.

\section{The decision}

One member in each group decides first on his/her contribution. When this member has made his/her decision, the other members of the group are informed of the amount of tokens he/she has contributed to the project. Thereafter the other group members decide.

The person, who decides first in a group remains the same for all 10 periods.

The person who decides first in a group will see the following input-screen:

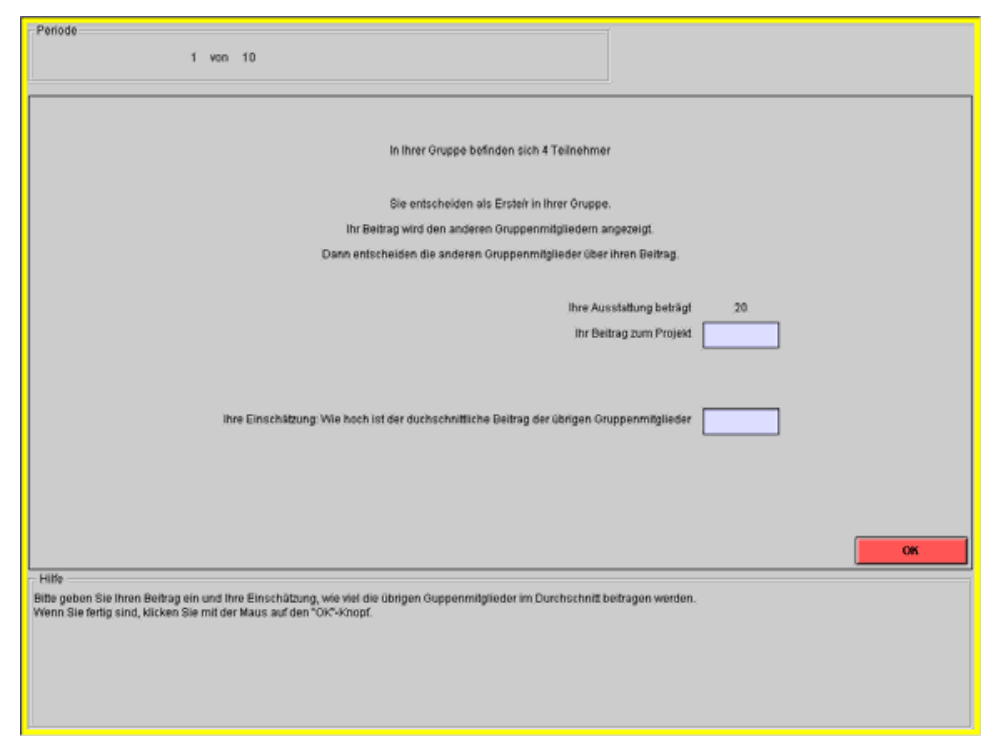

The period number appears in the top left of the screen. In the middle of the screen you will find the following information: Your group consists of 4 members. You are the person who decides first. Your contribution will be displayed to the other members of your group. Then they will decide on their contribution. Your endowment is 20 tokens.

If this screen appears on your monitor you are the member of your group who decides first. You take your decision by typing a number between 0 and 20 in the input field. This field can be reached by clicking it with the mouse. As soon as you have decided how many points to contribute to the project, you have also decided how many points you keep for yourself: This is (20 - your contribution) tokens. After entering your contribution you must press the O.K. button (either with the mouse, or by pressing the Enter-key). Once you have done this, your decision can no longer be revised.

Below the decision field is another input field labeled "My estimate: Other group member's average contribution". Please type in what you think will be the average contribution of the other three members in your group. In addition to your earnings from your decision you will be paid an extra amount depending on how close your estimate is to the actual average contribution of the other group members. If your estimate is exactly right 
or not more than 0.5 points away from the actual average payoff you will earn 20 points. If your estimate is further off than 0.5 points you will earn 10 points divided by the (absolute) distance between your estimate and the actual average contribution.

Please click O.K. as soon as you have made your decision and typed in your estimate. After you have made the decision the following input-screen will appear for the other three members of the group:

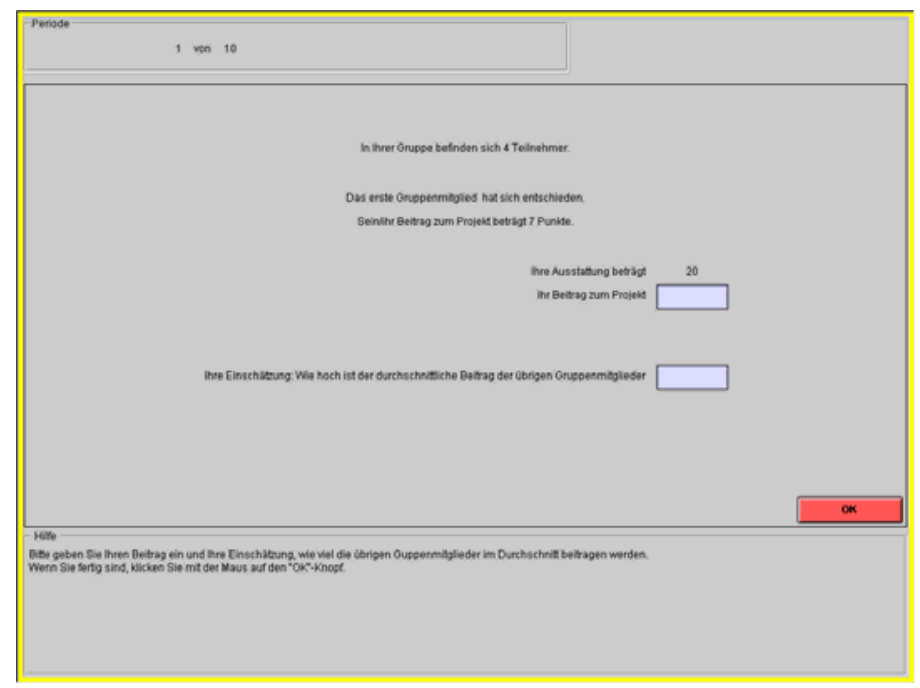

The contribution of the group member, who has made his/ her contribution decision first will be displayed. You take your decision by typing a number between 0 and 20 in the input field and confirm by pressing the O.K.button.

Please enter in the second input field labeled "My estimate:..." what you think is the average contribution of the other two group members. Here we ask you to estimate as accurately as possible what you think is the average contribution of the two group members that have not yet taken their decision. Please do not consider the decision of the group member that had decided first. In addition to your earnings from your decision you will be paid an extra amount depending on how close your estimate is to the actual average contribution of the two other group members. If your estimate is exactly right or not more than 0.5 points away from the actual average payoff you will earn 20 points. If your estimate is further off than 0.5 points you will earn 10 points divided by the (absolute) distance between your estimate and the actual average contribution.

After all three have taken their decision the following income-screen will be displayed for all group members:

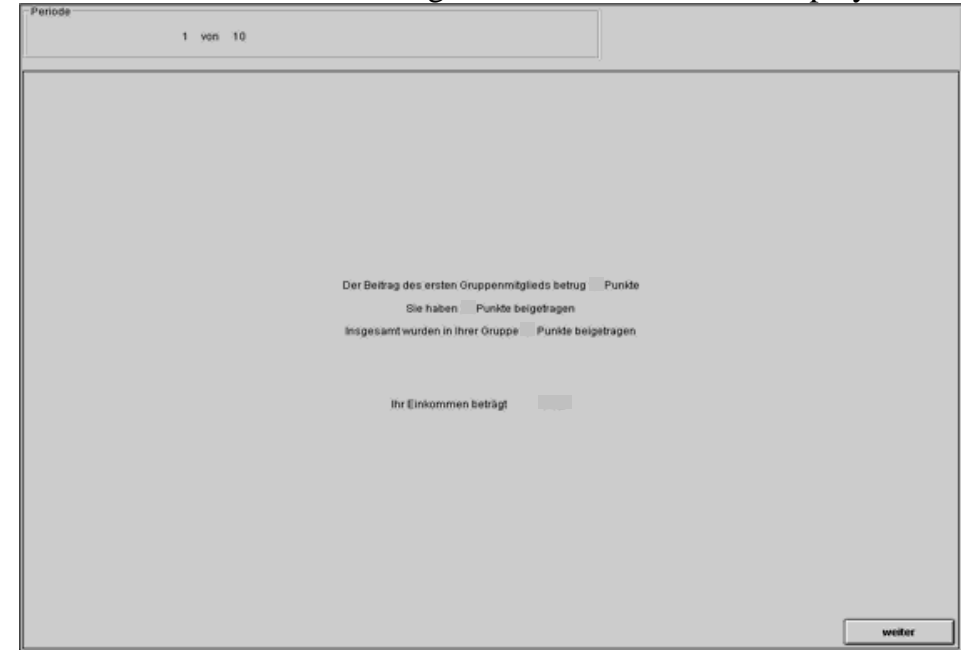

Your own contribution and the contribution of the member who has made his/her decision first in your group are displayed. Furthermore, you are informed about the total contribution of all group members (including your contribution) and your income from your decision in the current period. Do you have any questions? 